\title{
Effect of a Dual-task Virtual Reality Program for Seniors with Mild Cognitive Impairment
}

\author{
Jung-Ha Hwang ${ }^{1}$, Mi-Suk Park ${ }^{2}$ \\ ${ }^{1}$ Department of Occupational Therapy, Gwangyang Health Sciences University, Gwangyang, Korea \\ ${ }^{2}$ Department of Medical Laboratory Science, Gimhae College, Gimhae, Korea
}

\section{경도인지장애 노인에게 적용한 이중과제 병합 가상현실 프로그램의 효과}

황정하 ${ }^{1}$, 박미숙 ${ }^{2}$

${ }^{1}$ 광양보건대학교 작업치료과, ${ }^{2}$ 김해대학교 임상병리과

\begin{abstract}
This study examined the effects of a dual-task virtual reality program on the cognitive function and EEG for patients with mild cognitive impairment. A dual-task virtual reality program was performed in the experimental groups while conventional occupational therapy was carried out in the control group for 30 minutes per session, which was done five days per week for 6 weeks. The results were as follows. First, the memory of the cognitive function and balance was improved significantly in the experimental group with the dual-task virtual reality program compared to the control group with the traditional occupational therapy. Second, EEG was also increased significantly in the experimental group compared to the control group. The results of this study suggest that the dual-task virtual reality program was an effective treatment method for the elderly with mild cognitive impairment and would be a cornerstone of basic data that will be helpful to those suffering from a range of diseases.
\end{abstract}

Key words: Computerized neurocognitive function test, Dual-task virtual reality program, Electroencephalogram, Mild cognitive impairment

\footnotetext{
This is an Open Access article distributed under the terms of the Creative Commons Attribution Non-Commercial License (http://creativecommons.org/licenses/by-nc/4.0) which permits unrestricted non-commercial use, distribution, and reproduction in any medium, provided the original work is properly cited.

Copyright (c) 2018 The Korean Society for Clinical Laboratory Science. All rights reserved.
}

\author{
Corresponding author: Mi-Suk Park \\ Department of Medical Laboratory Science, \\ Gimhae College, 198 Saman-ro, 112 beon-gil, \\ Gimhae 50811, Korea \\ Tel: $82-55-320-1743$ \\ Fax: 82-55-336-6251 \\ E-mail: misuk0704@hanmail.net
}

Received: September 19, 2018 Revised $1^{\text {st. }}$ November 20, 2018 Revised $2^{\text {nd }}$ : November 28, 2018 Revised 3 ${ }^{\text {rd: }}$ November 30, 2018 Accepted: December 1, 2018

\section{서 론}

최근 우리나라는 고령사회에 진입하였고, 2026년에는 초고 령화 사회 진입을 예측하고 있으며, 이러한 인구 고령화 현상은 치매 발생 가능성을 급격히 증가시킬 것으로 예상된다[1].치매 의 임상 전 단계인, 경도인지장애(mild cognitive impairment, $\mathrm{MCI})$ 는 정상노화와 치매의 인지적 연속선상(cognitive continuum) 중간에 위치하고 있으며[2], 일상생활활동 수행과 지적 능력은 유지되나 전반적인 기억력 및 언어능력 등 부분적인 인
지기능 장애를 보이는 증상을 말한다[3]. 경도인지장애 기준을 살펴보면, 첫째 주관적인 기억력 장애, 둘째, 객관적인 기억력 장애, 셋째, 전반적으로 정상적인 인지기능, 넷째, 일상생활활 동은 전반적으로 보존, 다섯째, 치매가 아닌 경우를 말한다. 경 도인지장애 기준에 해당하는 인지기능은 일상생활을 수행할 수 있는 인지기능을 가지고 있으나, 정상 노인에 비하여 언어유창 성, 이름대기능력과 주의력 등의 저하를 보이며, 특히 기억력 손 상 중 단어회상 능력에 어려움을 나타낸다고 하였다[4].

현재 임상에서 널리 사용되고 있는 이중과제 훈련은 Plum- 
mer-D'Amato 등(2005)에 의하여 훈련이 시작되었고, 다양한 과제 간의 협응, 고도의 집중력과 인지 및 신체활동이 요구되어 지는 방법이며[5], 단일 과제 수행보다 이중 과제 수행 시 뇌의 더 넓은 영역이 활성화되고[6], 뇌 혈류량을 증가시키는 장점을 가지고 있다[7]. 뇌파 검사중 SMR (sensory motor rhythm)파 는 감각운동피질에서만 나타나 대상자의 각성과 학습능력과 연 관성이 깊고[8], Coben 등[9]의 연구에 따르면 알츠하이머 치 매 초기에는 알파파의 감소와 세타파의 증가를 보고하였다. 그 리고 Kang 등[10]의 연구에서는 집중력 과제가 포함된 컴퓨터 훈련 프로그램을 치매노인에게 적용하여 집중력 저하의 진행을 지연시키고 뇌 전체적인 활성의 증가를 확인하였으며, 인지재 활프로그램을 치매환자에게 실시하여 Fp1, Fp2 부위에서 베타 파의 유의한 증가를 보고한 연구도 있었다[11]. 더 나아가 베타 파는 정상 노인에서 가장 높고 알츠하이머병이 심해질수록 점 차 감소하는 것으로 보고되고 있으며[12], 많은 연구에서 경도 인지장애 노인들에게 운동을 통한 인지기능의 향상을 보고하고 있지만[13-14], 이중과제를 적용한 운동을 실시하여 뇌파 변화 를 연구한 내용은 거의 없었다. 본 연구에서 설계한 이중과제 중 재 프로그램이 경도인지장애 노인의 인지기능을 향상시키고, 이런 긍정적인 향상이 베타파와 SMR파에도 긍정적인 변화를 나타낼 것으로 사료된다.

최근 여러 가지 과제를 수행하고 현실과 유사한 상황에서 다 양한 기능 습득이 가능한 가상현실 프로그램 중재가 재활치료 에서 사용되고 있다[15]. 가상현실(virtual reality, VR)이란 컴 퓨터 하드웨어와 소프트웨어를 통해 사용자가 실제와 비슷한 경험을 할 수 있도록 만들어진 시뮬레이션이다[16]. 그리고 안 전한 환경에서 대상자 스스로 과제를 수행할 수 있으며 대상자 의 기능장애 정도에 따라 난이도를 조절할 수 있다는 이점 때문 에 대상자의 동기유발과 참여도가 높아져 최근 다양한 질환의 환자에게 사용되어지고 있다[17]. 하지만 기존의 가상현실 프 로그램만 적용하는 것은 효율성에서 떨어지며, 인지기능과 신 체활동의 복합적인 문제는 한 가지 방법보다는 두 가지 방법을 결합하여 적용하는 것이 더 효과적이라고 하였다[18]. 가상현 실에 이중과제 훈련을 실시한 Hill 등[19]에 의하면 인지장애와 치매에서 메타분석을 통한 가상현실 프로그램을 실시에서 보행 속도, 인지기능에서 유의한 향상을 보고하였다. 파킨슨 환자에 게 이중과제를 결합한 가상현실을 통해 평형 점수의 향상과 걸 음걸이, 보행 속도에서 유의한 차이를 보인 연구도 있었다[20].

지금까지의 문헌적 근거 하에서 연구를 고찰한 결과, 경도인 지장애 노인이 점차 증가하는 추세임을 알 수 있었고, 재활 훈련 의 경우 신체적 기능과 인지 기능을 분류한 각각의 재활방법보
다 두 가지 재활방법을 적용한 것이 더 효과적이라고 하였다 [21]. 또한, 대상자의 수행능력과 삶의 패턴 등이 포함된 치료적 접근 및 훈련 방법이 시행되어야 한다고 하였고, 작업치료적인 프로그램의 중재를 통한 실험 연구가 지속적으로 연구되어져야 한다고 하였다[22]. 하지만 대상자의 수행능력과 동기 부여를 제공할 수 있는 이중과제 병합 가상현실 프로그램을 경도인지 장애 노인에게 적용하여 결과를 나타낸 연구는 거의 없는 실정 이라고 하였다[23]. 이에 본 연구는 경도인지장애 노인에게 이 중과제 병합 가상현실 프로그램을 적용 시 대상자의 적극적인 참여 등을 통해 인지기능, 균형능력과 뇌파에서 변화를 나타낼 것으로 예상하였다. 따라서 본 연구의 목적은 이중과제 병합 가 상현실 프로그램이 경도인지장애 노인의 인지기능, 균형능력 과 뇌파에 미치는 효과를 검증하여 치매를 지연시킬 수 있는 프 로그램의 근거를 마련하고 임상에서 치료받고 있는 경도인지장 애 노인에게 적용 가능한 기초 자료를 제공하고자 한다.

\section{대상 및 방법}

\section{1. 연구 대상}

본 실험은 $\mathrm{G}$ 군과 $\mathrm{M}$ 시의 노인종합복지관을 이용하고 있는 노 인과 보건소에서 추천한 노인 중에서 대상자 선정 기준 중 $\mathrm{CDR}$ (clinical dementia rating)은 전문의 평가로 치매를 선별할 수 있으며 6개 일상생활활동 항목과 CDR 0, 0.5, 1, 2, 3, 4의 6 scale로 나뉘며, MMSE-K (mini mental state examinationKorean version)는 대상자의 인지를 가장 빠르게 평가할 수 있 는 도구로 12 개 항목과 총 30 점 만점으로 24점 이상은 정상, 20 점 미만은 치매 의심으로 판단할 수 있으며, BBS (berg balance scale)는 노인의 균형을 평가할 수 있는 평가도구로 14 개 항목 과 56점 만점으로 구성되어 있다. 본인이 이중과제 병합 가상현 실 프로그램에 참여를 희망하고 연구 목적에 동의하여 동의서 및 보호자 동의서를 제출한 연구 대상자로 구성하였고, 대구대 학교 생명윤리위원회의 심의를 거쳐 연구 진행에 대한 승인을 받았다(1040621-201702-HR-043-02). 연구 대상자의 일반 적인 특성은 다음과 같다(Table 1).

\section{2. 연구 과정}

1) 연구 절차

2017년 6월 26일부터 동년 8월 4일까지 G군과 M시의 노인 종합복지관을 이용하고 있는 노인과 보건소에서 추천한 노인 중 대상자 선정 기준을 고려하여, 본 연구의 취지를 이해하고 자 발적으로 참여에 동의한 40 명을 대상으로 연구를 실시하였다. 
Table 1. General characteristics of subject

\begin{tabular}{|c|c|c|c|c|}
\hline \multicolumn{2}{|c|}{ Category } & \multirow{2}{*}{$\begin{array}{c}\text { Experimental group }(\mathrm{N}=20) \\
8\end{array}$} & \multirow{2}{*}{$\begin{array}{c}\text { Control group }(\mathrm{N}=20) \\
9\end{array}$} & \multirow{2}{*}{$\frac{\chi^{2}}{.749}$} \\
\hline Sex & Male & & & \\
\hline & Female & 12 & 11 & \\
\hline Age (year) & Mean \pm SD & $74.45 \pm 6.20$ & $73.15 \pm 5.50$ & .500 \\
\hline \multirow[t]{4}{*}{ Weight (kg) } & $49 \geq$ & 2 & - & .552 \\
\hline & $50 \sim 59$ & 4 & 8 & \\
\hline & $60 \sim 69$ & 10 & 6 & \\
\hline & $70 \sim 79$ & 4 & 6 & \\
\hline \multirow[t]{4}{*}{ Education } & Uneducated & 12 & 9 & .314 \\
\hline & Elementary school & - & 11 & \\
\hline & Middle school & 7 & - & \\
\hline & High school & 1 & - & \\
\hline CDR & 0.5 rating & 20 & 20 & - \\
\hline MMSE-K & $\mathrm{M} \pm \mathrm{SD}$ & $22.35 \pm 0.74$ & $22.15 \pm 0.67$ & .389 \\
\hline BBS & & $38.25 \pm 4.75$ & $39.62 \pm 6.00$ & .474 \\
\hline
\end{tabular}

Abbreviations: BBS, Berg balance scale; CDR, Clinical dementia rating; MMSE-K, Mini-mental state examination-Korean version.

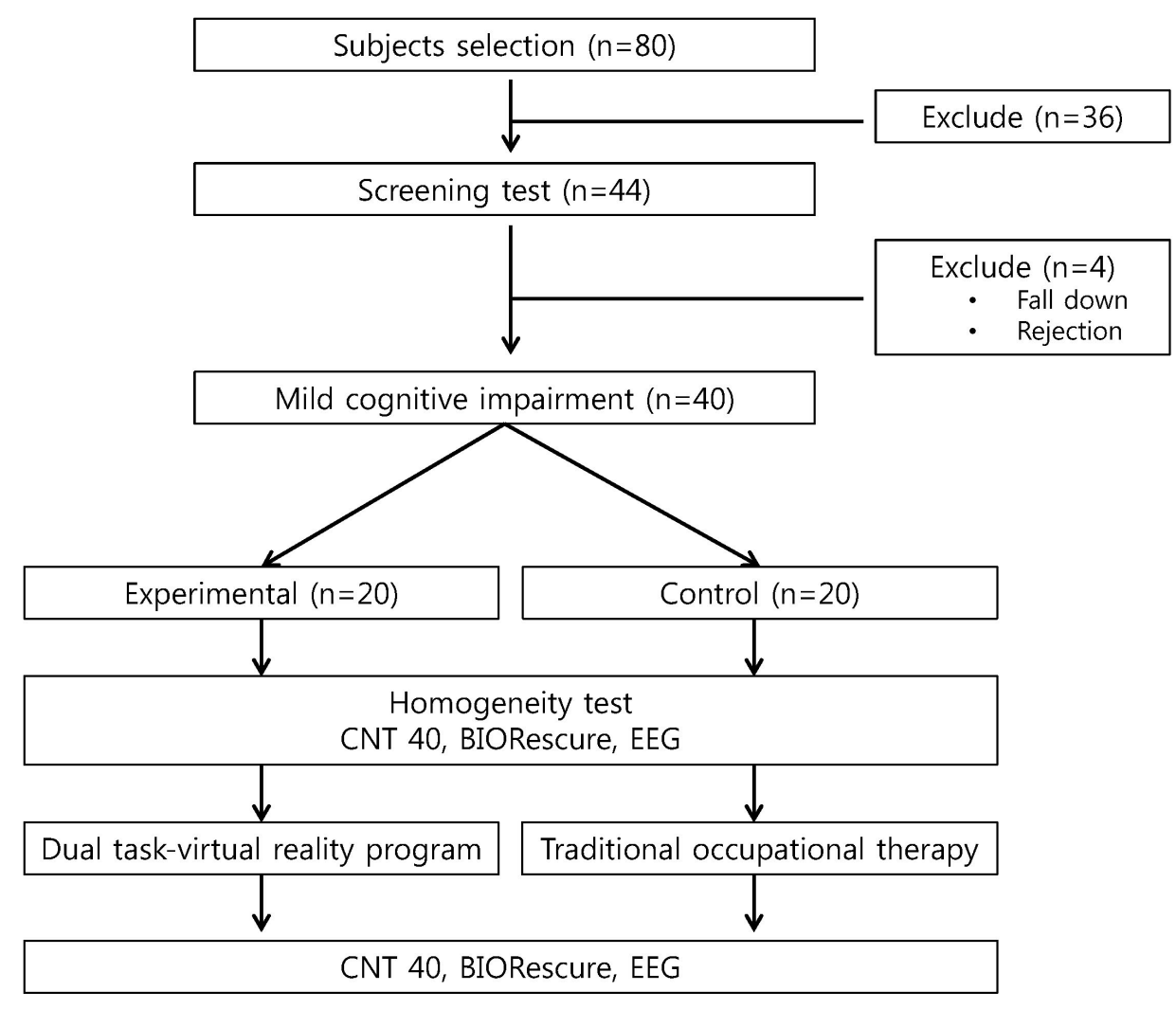

Figure 1. Experimental procedure. Abbreviation: EEG, electroencephalogram.

대상자 선정 기준은 외부의 보조 없이 $6 \mathrm{~m}$ 이상 보행이 가능한자, MMSE-K 점수가 23점 이하인 자, 대화와 읽기 그리고 의사소통 이 가능하고 연구 참여에 동의한 자를 선정하였다. 연구 참여자 의 탈락률을 줄이기 위하여 매 회기 프로그램 전날, 기관의 담당 자가 연구 대상자에게 프로그램이 있음을 알려주고 적극적으로 프로그램에 참여하도록 독려하였다. 연구의 시작은 44 명으로 실 시하였지만 중도에 4명이 탈락하였다. 대상자 선정 기준에 따라, 경도인지장애 노인을 선별하기 위하여 한국판 간이 정신상태 판
별검사(MMSE-K), 버그균형척도(BBS), 임상치매척도(CDR)를 사용하였다. 연구에 참여한 대상자는 중재 전 충분한 설명과 함 께자발적인 동의와보호자 동의를 얻은 후 컴퓨터 무작위 추출방 법을 적용하여 44 명이 참여하였다. 하지만 연구 철회 및 사고 등 의 이유로 4 명이 탈락하였으며, 최종적으로 총 40 명이 참여하였 다. 실험군과 대조군은 컴퓨터를 이용한 무작위 추출 방법을 사 용하여 집단을 구성하였다. 마지막으로 연구에서 사용된 이중과 제 병합 가상현실 프로그램은 대상자가 프로그램에 대해 충분하 
게 숙지하고 사전 교육을 받은 뒤 프로그램을 적용하였다. 본 연 구의 실험 절차를 요약하면 다음과 같다(Figure 1).

\section{2) 이중과제 병합 가상현실 프로그램}

키넥트 기반 시스템으로 구성된 XBOX360 시스템(Microsoft Co., Seoul, Korea)은 우리나라에 2006년 2월, 2010년 9월에 발매된 체감형 비디오 게임이다. 본 연구에서 사용된 "Kinect sports'는 탁구, 비치발리볼, 복싱, 그리고 볼링 경기를 실제상 황과 유사하게 즐길 수 있고 게임과 학습자 사이에 상호작용하 면서 즐길 수 있는 소프트웨어로 가상현실의 적용 효과를 알아 보고자 사용하였다(Figure 2). 이중과제 훈련은 단일과제 훈련 보다 인지과제, 균형, 보행능력에 있어서 더 효과적이라고 제안 하였다[24].

이에 본 연구에 이중과제가 포함된 가상현실 프로그램은 van Iersel 등[25]의 프로그램을 바탕으로 경도인지장애 노인의 인 지기능 정도를 고려하여 수정하였고, 작업치료과 교수 1 명, 경 도인지장애 노인을 대상으로 치료하고 있으며 10년 이상의 임 상경력이 있는 작업치료사 2 명과 물리치료과 교수 1 명의 자문 을 구하여 재구성하였다. 본 연구의 중재 프로그램 적용은 작업 치료사와 물리치료사 각 1 명이 참여하였고, 중재 전 실험군의 학습효과를 사전에 배제하기 위하여 인지과제 4가지 중 2가지 를 중재 전 무작위로 선택하였으며, 연구 대상자가 가상현실 프 로그램을 진행하는 동안 연구자는 인지과제를 하나씩 불러주면

Table 2. Double assignment merging virtual reality program contents

\begin{tabular}{ccc}
\hline Classification & $\begin{array}{c}\text { Double assignment merging virtual reality } \\
\text { program contents (Double assignment } \\
\text { program + Recognition contents) }\end{array}$ \\
\hline 1 & Beach volley ball & 1. tell numbers add, subtraction \\
2 & Ping-pong & 2. tell numbers backwards \\
3 & Bowling & 3. 3, 6, 9 hand clap \\
4 & Boxing & 4. tell words backwards \\
& 5. tell fruits names and animal \\
names alternately
\end{tabular}

서 진행하였다. 인지과제 내용은 다음과 같다(Table 2). 그리고 프로그램 진행 중 연구대상자가 피로를 호소할 경우 휴식시간 을 바로 제공하였으며, 프로그램이 끝날 때마다 3분 정도의 휴 식시간을 가진 후 다음 프로그램을 진행하였다. 연구자는 복지 기관에서 실시되는 프로그램이 대상자의 특성에 영향을 주는 변인으로 작용할 것을 고려하여 연구기간 중 시행되는 프로그 램은 작업시간, 휴식시간 그리고 참여 날짜 등은 임의로 조정함 으로써, 환경에 따른 불균형을 최소화하였다. 대조군은 전통적 인 작업치료를 적용하였고, 이것은 신경생리학적 이론에 기초 한 훈련과 일상생활훈련을 기반으로 한 치료를 의미하며 그 내 용에는 관절가동범위 훈련, 일상생활활동 훈련, 균형훈련과 인 지지각 발달 치료 등이 포함되었다. 실험군과 대조군은 동일하 게 1 일 30분씩 주5회, 총 6주간 실시하였으며 인지기능, 균형능 력과 뇌파의 사전, 사후 평가 결과는 일관성을 유지하기 위하여 연구가 시작되고 끝나는 금요일에 책임 연구자가 단독으로 평 가하였으며, 특히 뇌파는 연구 참여자가 의자에 앉아 XBOX360 시스템의 동영상을 시청하는 과정을 통해 측정하였다(Figure 3).

\section{3. 측정 도구}

1) 전산화 신경인지기능검사(Computerized neurocognitive function test)

신경인지기능검사(CNT40, Maxmedica, Seoul, Korea)는

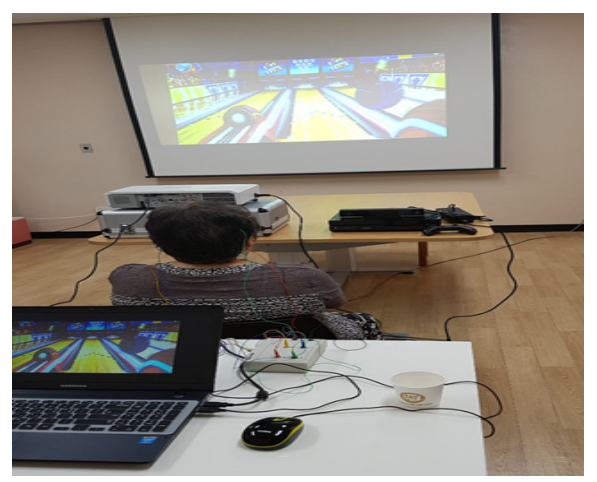

Figure 3. EEG measurement.
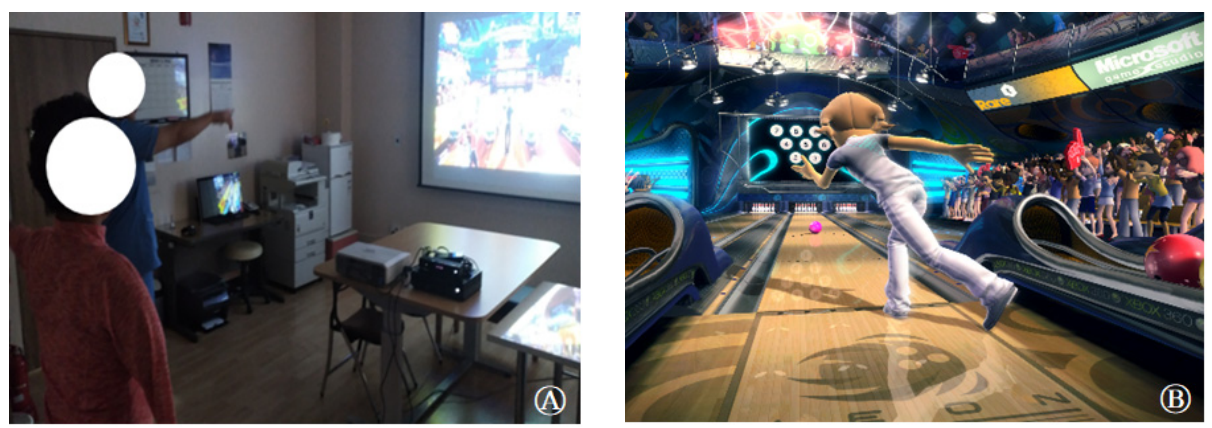

Figure 2. XBOX360 system (A, B). Implementation of Dual-task virtual reality program. 
주의력검사, 기억력 검사, 고위인지기능검사, 시운동 협응과 지 능검사 영역별로 표준화된 총 15 개의 프로그램으로 구성되었 다. 본 연구에서는 기억력을 평가할 수 있는 숫자 폭 검사(digit span test, DST) 중 숫자 바로 외우기(forward)와 숫자 거꾸로 외우기(backward)의 T-score 값을 사용하여 인지기능 변화를 알아보았다.

\section{2) BIORescue}

BIORescue (RM INGENIERIE, Rodez, France) 시스템은 힘을 여러 가지 방향으로 측정할 수 있는 감압 플랫폼과 RM사 의 동작분석 시스템으로 구성되어 있다. 본 연구에서는 체중 지 지 분배율의 변화를 알아보기 위하여 안정성의 한계(limit of stability: LOS)를 전 - 후 측정하였다. 이 장비의 검사-재검사 방법에는 급내상관계수(interclass correlation coefficient, ICC)는 0.840으로 높은 신뢰도를 나타냈다(Figure 4) [26].

\section{3) 뇌파(Electroencephalogram, EEG)}

뇌파 측정은 디지털 4채널 유선 뇌파측정기(QEEG-4 system, LAXTHA Inc, Daejeon, Korea)로 모노폴라(monopolar) 방식으로 입력하고, 감도는 $96.9 \mu \mathrm{V} \sim 806.5 \mu \mathrm{V}$ 로 16 단 계 조절이 가능하며, 뇌파신호의 초당 샘플링 빈도수는 $256 \mathrm{~Hz}$, 통과대역은 $0.7 \mathrm{~Hz} \sim 46 \mathrm{~Hz}(-3 \mathrm{~dB})$ 를 측정할 수 있다. 이렇게 측정된 뇌파 신호는 $12 \mathrm{bit} \mathrm{A} / \mathrm{D}$ 변환기를 통해 디지털 신호로 변 환되고 수신기에 신호를 전송한다. 전극에서 측정된 미약한 뇌 파 신호를 100 만 배 증폭시켜 생성한 원자료를 연결된 노트북 에 저장한 후 생체신호분석 소프트웨어 Telescan 프로그램을 사용하여 4채널의 상대파워(relative power)로 변환된 12 20 $\mathrm{Hz}$ 구간의 원 데이터를 연구 목적에 맞게 분석하였다. 뇌파 전 극은 10 20 국제 전극 배치법(international 10 20 electrode system)에 따라 본 연구에서는 Fp1 (frontopolar 1; 좌측 앞이

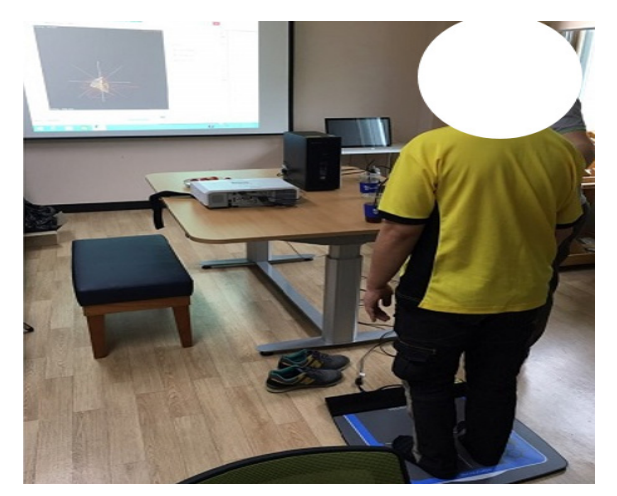

Figure 4. BIORescue system.
마엽), Fp2 (frontpolar 2; 우측 앞이마엽), T3 (tempolar 3; 좌 뇌 관자엽), T4 (tempolar 4; 우뇌 관자엽) 부위에 전극을 부착 하였고(Figure 3, red), 검은색과 회색의 기준 전극(reference electrode)은 좌/우측 꼭지돌기의 윗부분 뼈에 부착하였다. 사 용된 전극은 금으로 도포된 접시 형태의 디스크 전극이며, 뇌파 전용 풀(ElefixZ-401CE, Japan)을 묻혀 부착하였고, $3 \mathrm{M}$ 테이 프를 덮어서 전극이 떨어지지 않도록 머리 표면에 잘 고정될 수 있도록 하였다. 본 연구에서 측정한 $\beta$ 파는 경도인지장애, 알츠 하이머, 치매 등의 신경인지장애 정도를 $15 \sim 20 \mathrm{~Hz}$ 구간에서 측정하였고, $\beta$ 파중 가장 낮은 대역에 속하며, 뇌의 SMR파는 12 $15 \mathrm{~Hz}$ 에서 측정하였다[27]. 측정된 부위는 근전도 혼입이 많이 발생하는 부위로 웃거나 이마를 찡그리는 등의 안면 근육수축 과 몸 움직임이 발생하지 않도록 대상자에게 사전 교육을 시행 하였다. 또한, 측정 시 발생하는 여러 가지 간섭(interference) 을 배제하기 위하여 원 데이터(raw data)의 앞/뒤 10초는 제외 하였다.

\section{4. 자료처리 및 분석}

수집된 자료는 통계프로그램(SPSS version 20.0, SPSS Inc., Chicago, IL, USA)을 이용하여 통계 처리하였고, 연구 대상자 의 일반적 특성은 기술통계를 이용하여 빈도분석을 하였으며 집단 간 동질성 검사는 카이제곱 검정 $\left(\chi^{2}\right)$ 을 실시한 결과, 두 집 단 간 유의한 차이가 없었기 때문에 일반적 특성이 동일한 집단 임을 알 수 있었다. 우선, 집단 내 전, 후차이는 대응표본 $\mathrm{t}$-검정 을 사용하였고, 두 집단 간 변화량차이를 비교하기 위하여 독립 $\mathrm{t}$-검정을 사용하였다. 통계학적 유의수준 $P<0.05$ 로 하였다.

\section{결 과}

\section{1. 대상자들의 인지기능, 균형, 뇌파의 전 · 후 비교}

이중과제 병합 가상현실 프로그램을 적용한 대상자들의 인 지기능, 균형과 뇌파를 전 - 후 비교하였다. 인지기능의 정방향 은 중재 전 $3.51 \pm 0.61$ 점, 중재 후 $3.78 \pm 0.69$ 점, 역방향은 중 재 전 $2.64 \pm 0.76$ 점, 중재 후 $2.99 \pm 0.91$ 점이었고, 균형의 정적 인 항목은 중재 전 $1,179.35 \pm 81$ 점, 중재 후 $1,171 \pm 1,243$ 점, 뇌파의 SMR파와 $\beta$ 파를 포함한 모든 변인이 유의한 차이를 나 타내었다 $(P<0.05)$ (Table 3).

\section{2. 집단 간 인지, 균형, 뇌파 변화량 비교}

실험군과 대조군에게 이중과제 병합 가상현실 프로그램을 실시한 후 전 ·후차이의 변화량을 분석한 결과, 인지기능의 정 
Table 3. Comparison of recognition, balance and EEG (before vs after)

\begin{tabular}{|c|c|c|c|c|c|c|}
\hline \multirow{2}{*}{\multicolumn{3}{|c|}{ Group (N=40) }} & Before & After & \multirow{2}{*}{$t$} & \multirow{2}{*}{$P$} \\
\hline & & & \multicolumn{2}{|c|}{ Mean $\pm S D$} & & \\
\hline Recognition & Forward & $\mathrm{sec}$ & $3.51 \pm 0.61$ & $3.78 \pm 0.69$ & 2.959 & $.005^{*}$ \\
\hline & Reverse & & $2.64 \pm 0.76$ & $2.99 \pm 0.91$ & 2.100 & $.042^{*}$ \\
\hline Balance & Static & $\mathrm{mm}^{2}$ & $1,179 \pm 814$ & $1,711 \pm 1,243$ & 3.095 & $.004^{*}$ \\
\hline EEG & SMR (Fp1) & $\%$ & $0.07 \pm 0.03$ & $0.09 \pm 0.05$ & 2.026 & $.005^{*}$ \\
\hline & SMR (Fp2) & & $0.13 \pm 0.05$ & $0.18 \pm 0.09$ & 3.789 & $.001^{*}$ \\
\hline & SMR (T3) & & $0.13 \pm 0.17$ & $0.07 \pm 0.11$ & 2.319 & $.026^{*}$ \\
\hline & SMR (T4) & & $0.11 \pm 0.08$ & $0.18 \pm 0.13$ & 4.076 & $.000^{*}$ \\
\hline & $\beta(F p 1)$ & & $0.14 \pm 0.07$ & $0.18 \pm 0.11$ & 2.332 & $.002^{*}$ \\
\hline & $\beta$ (Fp2) & & $0.10 \pm 0.04$ & $0.17 \pm 0.11$ & 3.725 & $.001^{*}$ \\
\hline & $\beta$ (T3) & & $0.14 \pm 0.07$ & $0.20 \pm 0.12$ & 3.164 & $.003^{*}$ \\
\hline & $\beta$ (T4) & & $0.12 \pm 0.05$ & $0.18 \pm 0.11$ & 3.292 & $.002^{*}$ \\
\hline
\end{tabular}

${ }^{*} P<0.05$. Abbreviations: EEG, electroencephalogram; SMR, sensory motor rhythm.

Table 4. Compared variation between experimental group and control group

\begin{tabular}{|c|c|c|c|c|c|}
\hline \multirow{2}{*}{ Cause for change } & \multirow{2}{*}{\multicolumn{2}{|c|}{ Detail for change }} & Experimental group $(\mathrm{N}=20)$ & Control group $(\mathrm{N}=20)$ & \multirow{2}{*}{$P$} \\
\hline & & & \multicolumn{2}{|c|}{ Mean \pm SD } & \\
\hline \multirow[t]{2}{*}{ Recognition } & Forward & sec & $0.532 \pm 0.66$ & $0.00 \pm 0.24$ & $.003^{*}$ \\
\hline & Reverse & & $0.67 \pm 1.14$ & $0.07 \pm 0.61$ & $.016^{*}$ \\
\hline Balance & Static & $\mathrm{mm}^{2}$ & $1,081.70 \pm 1,213.08$ & $18.4 \pm 560.42$ & $.001^{*}$ \\
\hline \multirow[t]{8}{*}{ EEG } & SMR (Fp1) & $\%$ & $0.05 \pm 0.03$ & $0.00 \pm 0.08$ & $.003^{*}$ \\
\hline & SMR (Fp2) & & $0.09 \pm 0.08$ & $0.00 \pm 0.05$ & $.049^{*}$ \\
\hline & SMR (T3) & & $0.08 \pm 0.10$ & $0.01 \pm 0.04$ & $.001^{*}$ \\
\hline & SMR (T4) & & $0.14 \pm 0.09$ & $0.00 \pm 0.07$ & $.000^{*}$ \\
\hline & $\beta(\mathrm{Fp} 1)$ & & $0.12 \pm 0.10$ & $0.00 \pm 0.11$ & $.001^{*}$ \\
\hline & $\beta(\mathrm{Fp} 2)$ & & $0.14 \pm 0.10$ & $0.00 \pm 0.06$ & $.000^{*}$ \\
\hline & $\beta(\mathrm{T} 3)$ & & $0.11 \pm 0.14$ & $0.01 \pm 0.04$ & $.001^{*}$ \\
\hline & $\beta(\mathrm{T} 4)$ & & $0.10 \pm 0.09$ & $0.00 \pm 0.08$ & $.001^{*}$ \\
\hline
\end{tabular}

Abbreviations: See Table 3.

방향과 역방향, 균형의 정적인 항목과 뇌파의 SMR파와 $\beta$ 파에 서 유의한 차이를 나타내었다(Table 4).

\section{고 찰}

경도인지장애 노인은 증상이 진행될수록 광범위한 인지기능 장애가 나타나며, 근력 약화로 인한 자세 동요의 증가로 균형 유 지가 어려워지게 된다[28]. 본 연구는 종속변수 중 인지기능 변 화를 중점적으로 확인하는 연구로, 뇌파는 인지기능 변화에 추 가적인 근거자료로 사용하였으며, 균형은 대상자의 LOS 평가 및 중재를 통해 낙상 예방에 도움이 되는 기초자료를 제공하고 자 노력하였다. 본 연구의 첫 번째 연구 결과로, 초기 평가 점수 가 비슷한 대상자 40 명을 프로그램 적용 전, 후 인지기능의 평균 을 분석한 결과 정방향과 역방향에서 유의한 차이를 나타내었 고, 실험군과 대조군을 각각 20 명씩으로 나누어 전 - 후 비교량
을 분석한 결과에서도 유의미한 차이를 나타내었다. 이 결과는 이중과제 병합 가상현실 프로그램을 적용한 실험군이 대조군에 비해 인지기능의 기억력 항목이 긍정적으로 향상되었다는 것을 의미하며, 복합 과제를 통해 경도인지장애 노인의 인지기능 항 목의 향상을 보인 선행 연구와 일치하는 결과이다[29]. 하지만 본 연구에서는 숫자 폭 검사의 바로 외우기와 거꾸로 외우기 항 목은 유의한 변화를 관찰할 수 있었다. 이는 Hwang 등[23]이작 성한 연구와 같은 결과를 도출하였지만, 많은 선행연구와 상반 된 결과를 보인 것은 선행연구의 대상자 수, 측정자의 변수, 이 종표본, 회기 수 등으로 인해 다른 결과를 보인 것으로 생각된 다.

최근 메타연구를 실시한 Gates 등[30]의 연구에 의하면 단일 운동효과의 결과가 인지기능 개선에 확실한 효과가 없음을 보 고하였으며, 최근 이중과제와 접목한 다각적 중재 프로그램은 단일 과제보다 인지기능의 긍정적인 효과를 보고하고 있다. 
이를 토대로 본 연구에서 적용한 이중과제 병합 가상현실 프 로그램은 연구 대상자 능력에 따른 난이도 조절을 통해 흥미와 참여도를 이끌어낼 수 있는 중재로 구성하였다. 실제로 프로그 램 적용 시 연구에 참여한 대상자들은 훈련시간이 끝났음을 알 렸을 때는 아쉬움을 나타내었고 프로그램이 시작되었을 때는 휴식시간을 거치지 않고 지속적으로 하려는 의욕을 보였다. 또 한 연구 대상자가 프로그램에 참여할 때마다 무엇인가를 이루 고자 하는 내적 욕구와 함께 집중하는 모습을 확인할 수 있었다. 그리고 프로그램 과정 중 연구 대상자의 치료적 적응도가 높아 져 더 이상의 탈락자 없이 회기를 무사히 마칠 수 있었다. 이는 가상현실 기반 프로그램이 대상자의 동기를 부여하고 몰입적인 선행연구를 뒷받침하며[31], 주관적 기억력을 호소하는 대상자 에게 부합되는 훈련 방법이라고 판단된다. 또한 이중과제 병합 가상현실 프로그램에는 계산하기, 과일이름 말하기, 글자 거꾸 로 말하기와 박수치기 등과 같은 인지과제가 포함되어 있어 기 억력과 주의력이 더 향상을 나타낸 것으로 사료된다. 따라서 경 도인지장애 노인의 인지기능 치료는 대상자의 수준이 고려된 과제를 선택하고 한 가지의 과제보다는 복합적으로 이루어진 과제를 적용하는 것이 더 효과적일 것이라는 것을 본 연구의 결 과가 시사한다.

본 연구의 두 번째 결과로, 프로그램 적용 전, 후 균형기능을 평균 분석한 결과 정적인 항목에서 유의한 차이를 나타내었고, 실험군과 대조군을 각각 20명씩으로 나누어 전 - 후 비교량을 분석한 결과에서도 통계학적으로 유의한 차이를 보였다. 이 결 과는 이중과제 병합 가상현실 프로그램을 적용한 실험군이 전 통적인 작업치료를 적용한 대조군에 비해 균형능력 항목이 통 계학적으로 유의하게 향상되었다는 것을 의미한다. Pichierri 등[18] 연구에서 15 명의 노인을 대상으로 인지와 운동이 복합 된 이중과제를 병합한 가상현실 프로그램을 적용하여 균형능력 의 유의한 차이를 보고하였다. 그리고 Montero-Odasso 등 [32]의 연구에 따르면 경도인지장애 노인 43명과 대조군 25명 에게 이중과제를 적용한 결과, 보행속도와 낙상의 위험률이 감 소하는 것을 보고하였다. 본 연구에서 사용한 Kinect 기반 $\mathrm{XBOX} 360$ 프로그램은 컨트롤로 없이 가상환경 속에서 대상자 의 몸을 자유롭게 움직이는 동작을 요구하고 다양한 프로그램 을 실시하면서 더욱 역동적인 활동을 요구하기 때문에 더 높은 운동 조절을 필요로 한다. 따라서 본 연구에서 적용한 프로그램 들을 수행하는 것이 체간의 안정성과 대칭성을 유지하고 섬세 한 동작을 만들어내어 균형능력의 향상을 나타낸 것으로 사료 된다.

뇌파는 인체에 영향을 주지 않고 비침습적인 방법을 사용하
여 대뇌기능을 평가할 수 있는 검사도구로 인간의 의식 상태와 기억력과 집중력 등 인지기능의 변화를 측정할 수 있는 장비이 다[33]. 본 연구에서도 이중과제 병합 가상현실 프로그램을 경 도인지장애 노인에게 적용 프로그램 적용 전, 후 뇌파를 평균 분 석한 결과 Fp1, Fp2, T3, T4부분에서 유의한 차이를 나타내었 고, 실험군과 대조군을 각각 20 명씩으로 나누어 전 - 후 비교량 을 분석한 결과에서도 통계학적으로 유의한 차이를 보였다.

이러한 결과는 주의력 능력이 향상될수록 뇌의 이마-마루엽 부분의 활성화를 보고한 연구와 일치하는 결과로[34], 프로그 램을 적용한 실험군이 대조군에 비해 뇌파 세기가 긍정적으로 향상되었다는 것을 의미한다. 본 연구와 같은 결과를 보인 Jiang[35]의 연구에서는 경도인지장애 노인 35 명에게 작업 기 억(working memory) 과제를 적용하여 뇌파의 $\alpha$ 파, $\beta$ 파와 $\theta$ 파 세기에서 유의하게 변화를 보고하였다. 따라서 이중과제 병합 가상현실 프로그램 훈련을 통해 뇌파의 변화가 증진되었으므 로, 이 훈련이 경도인지장애 노인의 인지기능 중 기억력을 향상 시키는데 효과적임을 보여주는 근거가 될 수 있을 것으로 사료 된다. 또한 Lee[36]의 연구는 본 연구와 비슷한 절차로 연구를 진행하였지만, 본 연구에서 적용한 평가도구와 중재 프로그램 은 객관적이고 타당한 컴퓨터 장비를 사용하여 결과를 도출한 점, 종속변수의 종류와 뇌파 결과 도출 방식 등이 다른 것을 확인 할 수 있었다. 하지만 인지과제가 포함된 중재 프로그램을 적용 하여 알파파와 베타파 부분에서 변화를 보인 것은 본 연구 결과 와 일치하는 것을 확인할 수 있었다.

Bherer 등[37]의 연구에 의하면 인지과제가 포함된 이중과 제 병합 가상현실 프로그램은 운동과 인지기능을 동시에 수행 함으로써 협응 기술과 인지기능의 향상을 보인다고 하였는데, 본 연구에서도 개별적인 경도인지장애 노인의 참여에 대한 기 회 제공과 인지과제가 결합된 프로그램을 적용하여 기억력의 인지기능, 균형과 뇌파에 긍정적인 효과를 나타낸 것은 노화로 인한 인지기능의 감퇴를 보이는 대상자들에게 적용 가능하고, 실제 국내 작업치료 임상에서 경도인지장애 노인을 치료 및 훈 련하는데 유용한 근거가 될 수 있을 것으로 생각된다.

\section{요 약}

본 연구는 이중과제 병합 가상현실 프로그램을 경도인지장 애 노인에게 적용하여 인지기능, 균형과 뇌파에 미치는 영향을 알아보았다. 이중과제 병합 가상현실 프로그램을 중재한 실험 군 집단과 전통적인 작업치료를 중재한 대조군 집단은 1 회 30 분, 1 주일 5 회, 총 6 주에 걸쳐 실시하였다. 연구 결과는 첫째, 이 
중과제 병합 가상현실 프로그램을 시행한 실험군이 전통적인 작업치료를 시행한 대조군에 비해 인지기능 중 기억력 항목과 균형 항목에서 유의하게 증가하였다. 둘째, 이중과제 병합 가상 현실 프로그램을 시행한 실험군이 전통적인 작업치료를 시행한 대조군에 비해 $\beta$ 파와 SMR파의 세기가 유의하게 증가하였다. 결과를 종합해보면, 이중과제 병합 가상현실 프로그램이 경도 인지장애 노인에게 효과적인 치료방법이었고, 다양한 질환을 겪고 있는 대상자들에게 도움이 되는 기초 자료의 초석이 되기 를 바란다.

\section{Acknowledgements: None}

Conflict of interest: None

Author's information (Position): Hwang $\mathrm{JH}^{1}$, Professor; Park MS ${ }^{2}$, Professor.

\section{REFERENCES}

1. Koh JJ. A review of long-term care insurance for the elderly by access to an aging society. Law and Policy. 2018;24:27-61.

2. Petersen RC, Mild cognitive impairment as a diagnostic entity. J Intern Med. 2004;256:183-194. https://doi.org/10.1111/j.13652796.2004.01388.x.

3. Winblad B, Palmer K, Kivipelto M, Jelic V, Fratiglioni L, Wahlund LO, et al. Mild cognitive impairment-beyond controversies, towards a consensus: Report of the international working group on mild cognitive impairment. J Intern Med. 2004;256:240-246. https://doi.org/10.1111/j.1365-2796.2004. 01380.x.

4. Bruno D, Reiss PT, Petkova E, Sidtis JJ, Pomara N. Decreased recall of primary words predicts cognitive decline. Arch Clin Neuropsychol. 2013;28;95-103. https://doi.org/10.1093/arclin/acs116.

5. Pulummer-D'Amato P, Altmann LJ, Behrman AL, Marseske M. Interference between cognition, double-limb support, and swing during gait in community-dwelling individuals poststroke. Neurorehabil Neural Repair. 2010;24:542-549. https://doi.org/10.1177/1545968309357926.

6. Lee BT, Lee KM. Neural basis involved in the interference effects during dual task: interaction between calculation and memory retrieval. The Korean Society for Cognitive Science. 2007;18: 159-178. https://www.kci.go.kr/kciportal/landing/article.kci?arti_ id=ART001064316.

7. Erickson KI, Colcombe SJ, Wadhwa R, Bherer L, Peterson MS, Scalf PE, et al. Training-induced functional activation changes in dual-task processing: an FMRI study. Cereb Cortex. 2007; 17:192-204. https://doi.org/10.1093/cercor/bhj137.

8. Kim CS. Analysis of the continuous monitored electroencephalogram patterns in intensive care unit. Korean J Clin Lab Sci. 2017;49:294-299. https://doi.org/10.15324/kjcls2017. 49.3.294.
9. Coben LA, Danzinger W Storandt M. A longitudinal EEG study of mild senile dementia of Alzheimer's type: changes at 1 year and 2.5 years. Electroencephalogr Clin Neurophysiol. 1985; 61:101-112. https://doi.org/10.1016/0013-4694(85)91048-X.

10. Kang WK, Kang MH, Yang JL, Ku EJ, Kim SK. The comparison of EEG activity by computer assisted cognitive rehabilitation program in the normal elderly and the elderly with dementia. Korean Soci Occupat. 2009;17:1-13.

11. Lee HJ, Hwang KO. The effects of cognitive rehabilitation program on EEG for patients with vascular dementia. J Spec Edu \& Rehab Sci. 2014;53:213-230. https://doi.org/10.15870/jsers. 2014.06.53.2.213.

12. Baker M, Akrofi K, Schiffer R, Boyle MW. EEG patterns in mild cognitive impairment (MCI) patients. Open Neuroimag J. 2008;2:52-55. https://doi.org/10.2174/1874440000802010052.

13. Heyn P, Abreu BC, Ottenbacher KJ. The effects of exercise training on elderly persons with cognitive impairment and dementia: A meta-analysis. Arch Phys Med Rehabil. 2004;85: 1694-1704. https://doi.org/10.1016/j.apmr.2004.03.019.

14. Smiley-Oyen AL, Lowry KA, Francois SJ, Kohut ML, Ekkekakis P. Exercise, fitness, and neurocognitive function in dlder adults: The "selective improvement" and "cardiovascular fitness" hypotheses. Ann Behav Med. 2008;36:280-291. https://doi.org/ 10.1007/s12160-008-9064-5.

15. Deutsch JE. Using virtual reality to improve walking post-stroke: translation to individuals with diabetes. J Diabetes Sci Technol. 2011;5:309-314. https://doi.org/10.1177/ 193229681100500216.

16. Rizzo AA, Buckwalter JG. Virtual reality and cognitive assessment and rehabilitation: The state of the art. Stud Health Technol Inform. 1997;44:123-146. https://doi.org/10.3233/ 978-1-60750-888-5-123.

17. Grealy MA, Johnson DA, Rushton SK. Improving cognitive function after brain injury: The use of exercise and virtual reality. Arch Phys Med Rehabil. 1999;80:661-667. https://doi.org/10.1016/S0003-9993(99)90169-7.

18. Pichierri G, Wolf P, Murer K, de Bruin ED. Cognitive and cognitive-motor interventions affecting physical functioning: A systematic review. BMC Geriatr. 2011;11:1-19. https://doi.org/ 10.1186/1471-2318-11-29.

19. Hill NT, Mowszowski L, Naismith SL, Chadwick VL, Valenzuela M, Lampit A. computerized cognitive training in older adults with mild cognitive impairment or dementia: a systematic review and meta-Analysis. Am J Psychiatry. 2017;174:329-340. https://doi.org/10.1176/appi.ajp.2016.16030360.

20. Mirelman A, Maidan I, Herman T, Deutsch JE, Giladi N, Hausdorff JM. Virtual reality for gait training: can it induce motor learning to enhance complex walking and reduce fall risk in patients with parkinson's disease?. J Gerontol A Biol Sci Med Sci. 2011;66:234-240. https://doi.org/10.1093/gerona/glq201.

21. Kim KM, Park HT, Park JH, Lim ST, Kwon YC, Park KW. The effect of dual task exercise on gait parameter in mild cognitive impairment. J Sport Sci. 2017;26:1065-1073.

22. Mountain G, Mozley, Craig C, Ball L. Occupational Therapy led health promotion for older people: feasibility of the lifestyle matters program. British J Occupation Ther. 2008;71:406-413. https://doi.org/10.1177/030802260807101002. 
23. Hwang JH, Lee SM. The effect of virtual reality program on the cognitive function and balance of the people with mild cognitive impairment. J Phys Ther Sci. 2017;29:1283-1286. https://doi.org/10.1589/jpts.29.1283.

24. Her JG, Park KD, Yang YA, Ko TS, Kim HS, Lee JS, et al. Effects of balance training with various dual-task conditions on stroke patient. J Phys Ther Sci. 2011; 23:713-717. https://doi.org/10.1589/jpts.23.713.

25. van Iersel MB, Ribbers H, Munneke M, Born GF, Rikkert MG. The effect of cognitive dual tasks on balance during walking in physically fit elderly people. Arch Phys Med Rehabil. 2007;88:187-191. https://doi.org/10.1016/j.apmr.2006.10.031.

26. Song GB, Park EC. The effects of balance training on balance pad and sand on balance and gait ability in stroke patients. J Korean Soc Phys Med. 2016;11:45-52. https://doi.org/10. 13066/kspm.2016.11.1.45.

27. Dierks T, Jelic V, Pascual-Marqui RD, Wahlund LO, Julin P, Linden DE, et al. Spatial pattern of cerebral glucose metabolism(PET) correlates with localization of intracerebral EEG-generators in Alzheimer's disease. Cli Neur, 2000;111: 1817-1824. https://doi.org/10.1016/S1388-2457(00)00427-2.

28. Spirduso WW, Francis K, Eakin T, Stanford C. Quantification of manual force control and tremor. J Mot Behav. 2005;37: 197-210. https://doi.org/10.3200/JMBR.37.3. 197-210.

29. You JH, Shetty A, Jones T, Shields K, Belay Y, Brown D. Effects of dual-task cognitive gait intervention on memory and gait dynamic in olders adults with a history of falls: A preliminary investigation. Neuro Rehabilitation. 2009;24:193-198. https:// doi.org/10.3233/NRE-2009-0468.

30. Gates N, Fiatarone Singh MA, Sachdev PS, Valenzuela M. The effect of exercise training on cognitive function in older adults with mild cognitive impairment: A meta-analysis of randomized controlled trials. Am J Geriatr Psychiatry. 2013;21:10861097. https://doi.org/10.1016/j.jagp.2013.02.018.

31. Deutsch JE, Borbely M, Filler J, Huhn K, Guarrera-Bowlby P. Use of a low-cost, commercially available gaming console(Wii) for rehabilitation of an adolescent with cerebral palsy. Phys Ther. 2008;88:1196-1207. https://doi.org/10.2522/ptj.20080062.

32. Montero-Odasso M, Muir SW, Speechley M. Dual-task complexity affects gait in people with mild cognitive impairment: The interplay between gait variability, dual tasking, and risk of falls. Arch Phys Med Rehabil. 2012;93:293-299. https://doi.org/10. 1016/j.apmr.2011.08.026.

33. Putman JA. EEG biofeedback on a female stroke patient with depression: A case study. J Neurother. 2001;5:27-38. https:// doi.org/10.1300/J184v05n03_04.

34. Macaluso E, Eimer M, Frith CD, Driver J. Preparatory states in crossmodal spatial attention: spatial specificity and possible control mechanisms. Exp Brain Res. 2003;149:62-72. https:// doi.org/10.1007/s00221-002-1335-y.

35. Jiang ZY. Study on EEG power and coherence in patients with mild cognitive impairment during working memory task. J Zhejiang Univ Sci B. 2005;6:1213-1219. https://doi.org/10. 1631/jzus.2005.B1213.

36. Lee HJ. The effect of the cognitive rehabilitation upon EEG and Cognition in the Alzheimer's dementia. Korean J Soc Sci. 2010;5:1217-1226.

37. Bherer L, Kramer AF, Peterson MS, Colcombe S, Erickson K, Becic E. Training effects on dual-task performance: Are there age-related differences in plasticity of attentional control?. Psychol Aging. 2005;20:695-709. https://doi.org/10.1037/08827974. 20.4.695. 